"This is the peer reviewed version of the following article: Melser, D. and Lee, A. D. (2014), Estimating the Excess Returns to Housing at a Disaggregated Level: An Application to Sydney 2003-2011. Real Estate Economics, 42: 756-790, which has been published in final form at 10.1111/1540-6229.12057. This article may be used for non-commercial purposes in accordance with Wiley Terms and Conditions for Self-Archiving." 


\title{
Estimating the Excess Returns to Housing at a Disaggregated Level: An Application to Sydney 2003-11
}

\author{
Daniel Melser \\ Email: danielmelser@hotmail.com \\ Economics Discipline Group \\ University of Technology, Sydney \\ Ultimo, NSW 2007 \\ Australia
}

\author{
Adrian Lee \\ Email: adrian.lee@uts.edu.au \\ Finance Discipline Group \\ University of Technology, Sydney \\ Ultimo, NSW 2007 \\ Australia
}

Draft: February 17, 2012*

\begin{abstract}
The returns to housing are particularly important because this asset class makes up such a large fraction of household wealth. Yet they are not straightforward to calculate given both the heterogeneity in homes and the fact they sell only infrequently. We outline a methodology for constructing the excess returns to housing at a disaggregated level, essentially that of the individual home. Our approach explicitly takes account of the inherent risk in homeownership with regard to the capital gain or loss component of housing returns. This approach is applied to a rich data set for Sydney, Australia, from 2003Q1 to 2011Q2. Our findings indicate that the returns to housing are on average quite weak though they exhibit significant diversity across dwelling types and regions. Excess returns are also strongly influenced by assumptions regarding the level of risk aversion.
\end{abstract}

Keywords: Hedonic regression, housing, excess returns, risk.

JEL Classification Codes: E31, G14, R30.

*Note, this draft is preliminary please do not quote or distribute it without express permission from the authors. This research was assisted by a UTS Business School research grant which is gratefully acknowledged. The authors would also like to thank Australian Property Monitors (APM) for the provision of data. However, the opinions expressed are solely those of the authors. 


\section{Introduction}

Housing has a vital dual role in the economy. It is a key component of the capital stock in terms of providing shelter services to households while also being an important asset class given that housing makes up a large part of overall wealth. In the US, the Federal Reserve's Flow of Funds Accounts indicate that the value of real estate assets owned by households was around US\$18.3 trillion at the end of 2011. This amounted to more than a quarter of households' total asset holdings and much more than this prior to the recent collapse in house prices. In Australia, which is the focus of the empirical application that follows, real estate is a much more important asset class. The Australian Bureau of Statistics (ABS) estimates that owner occupied housing makes up well over half of household wealth (ABS, 2010). It is perhaps surprising, given that housing is such a key asset class, that more is not known about the properties of its returns. In particular, how has residential real estate performed relative to other asset classes?

In this article we are interested in the question of how well households have done by purchasing a home rather than following some other investment strategy, such as renting a home and employing their capital elsewhere. While this question is a natural one, answering it is not entirely straightforward. Residential dwellings are heterogeneous - no two homes are alike - and unfortunately the sale prices of individual homes are observed infrequently. This is in stark contrast to many other types of assets, such as bonds or stocks, which are homogeneous and traded almost continuously on highly liquid markets. This makes calculating the return to home ownership more difficult than for other investments.

In a seminal paper Case and Shiller (1989) (see also Case and Shiller, 1990) estimated the excess returns to residential real estate in four cities; Atlanta, Chicago, Dallas and San Francisco. They noted that the return to housing has two major components. First, just like a stock or bond there is the yield - this is the rent that can be achieved on the property for a housing investor of the rental payments avoided in the case of owner-occupiers. Second, there is the capital gain/loss through the revaluation of the asset. They constructed estimates of the city-wide appreciation rate of homes using transactions data and the repeat sales method of Bailey, Muth and Nourse (1963). They lacked detailed rental data so essentially assumed a fixed rate for the rental yeild. This was apparently $5 \%$ across cities in Case and Shiller (1989) and $6.9 \%$ for Atlanta, $5.0 \%$ for Chicago, $11.1 \%$ for Dallas and $9.0 \%$ for San Francisco in Case and Shiller (1990). Using this approach they were able to compute the average return to housing which they compared with a 1-year Treasury Bill to calculate the excess return. In Case and Shiller (1990), over the period from 1970-86, these excess returns averaged $4.22 \%$ per annum for Atlanta, 2.70\% for Chicago, $7.31 \%$ for Dallas and a whopping $20.77 \%$ for San Francisco. ${ }^{1}$ This led Case and Shiller (p.136, 1990) to conclude that,

\footnotetext{
${ }^{1}$ These figures are calculated as an average of the numbers in Table 3 of Case and Shiller (p.261, 1990) for the respective cities. The averages presented at the bottom of the table are all zero but this is clearly a typo.
} 
...it is somewhat surprising that excess returns of this magnitude could persist for so long a period of time. In one sense, we know a "buy rule" that will consistently earn an extraordinary return: simply buy housing.

More recent work has apparently found similarly robust returns to housing. Flavin and Yamashita (2002), in their examination of housing's role in the portfolio, constructed estimates of the return to housing and its variance. They used owner price valuations from the Panel Survey of Income Dynamics (PSID) from 1968-92 to estimate the capital gain to homeowners while adopting a similar approach to that of Case and Shiller $(1989,1990)$ to derive rents. This yielded estimates of the annual real return to housing of $6.59 \%$ with a standard deviation of $14.24 \%$. Because the real return on Treasury Bills and bonds was essentially zero we can equate their real return on housing to an excess return in line with the approach in Case and Shiller $(1989,1990)$. According to Flavin and Yamashita (2002) housing had a very attractive risk-return profile. Its returns were broadly comparable with those on stocks but the standard deviation of stocks was almost $70 \%$ higher.

Hasanov and Dacy (2009) undertook a similar exercise to that of Flavin and Yamashita (2002) and constructed aggregate returns to housing from 1952-2005. The main difference is in their data sources. Hasanov and Dacy (2009) use aggregate data. They construct estimates of the capital gain to homeownership from the Federal Reserve's Flow of Funds Accounts and use the BEA's National Income and Product Accounts to measure the rental yield. Over the period they estimated annual real returns of $6.92 \%$ for homeowners with a standard deviation of $4.89 \%$. While the real return is similar to that of Flavin and Yamashita (2002) the lower standard deviation likely reflects the authors' use of aggregate information in constructing housing returns rather than unit record data.

The various estimates of the excess returns to housing point it being a very attractive investment class. Yet we argue that these estimates may not have provided the full picture with regard to housing for two key reasons.

First, the standard approach to estimating the capital gains to housing reflects the appreciation of a portfolio of homes in some city or region rather than that for a specific home. This is important because within a city there are likely to be many housing sub-markets, determined by geography and by property type (Bourassa, Hoesli and Peng, 2003), and each of these submarkets may have different appreciation rates. A household usually owns only a single home so their capital gain may vary significantly depending upon where and what type of property they have. There is a great deal of diversity in the appreciation rate across homes. When Case and Shiller (1989) regressed the price changes of individual homes on the average city-wide change “...the $R^{2}$ is only 0.066 for Atlanta, 0.158 for Chicago, 0.121 for Dallas, and 0.270 for San Francisco." This indicates that there is a fairly low correlation between the rate of appreciation on individual homes and city-wide movements. Cannon, Miller and Pandher (2006) compare MSA dwelling price movements with those at the ZIP code level and find 
that the former account for less than $20 \%$ of price change. The calculations of the return to housing have been divorced from the reality that different properties within a market tend to perform quite differently. Hence the returns to housing have been much more diverse than may be readily apparent.

However, detailed data at a disaggregated level is now widely available meaning that we can construct housing returns essentially at the level of the individual home. In this paper we have at our disposal data on sale prices, rents and characteristics of individual dwellings across Sydney from 2003Q1 to 2011Q2. With this data we aim to construct estimates of the returns across the entire spectrum of dwelling-types. This provides a level of detail which has hitherto been absent in the discussion of real estate market returns. But constructing these returns is not straightforward. As noted, homes are heterogenous assets and a given property does not sell very often. Hence in order to estimate the capital gains for specific classes of homes we make extensive use of hedonic regression methods to impute prices and rents at a disaggregated level. We show that the hedonic models which underlie this imputation, and allow for disaggregated price trends, are more strongly supported by the data than those specifications which do not allow for such flexible price trends.

Second, greater attention is required on how the risky aspect of housing investment is balanced against the return. It is a point which hardly bears mentioning; assets which are higher-risk also generally have higher returns. Indeed, Cannon, Miller and Pandher (2006) found just such a pattern when they examined the cross section of MSA home price appreciation rates and their variance. Risk has not been explicitly treated by many in their examination of the excess returns to housing. Others, such as Flavin and Yamashita (2002), have used a mean-variance portfolio allocation framework which explicitly takes account of the variance of housing in constructing optimal portfolio shares. But this only obliquely addresses the question of excess returns. The shares that come out of their optimization problem do not provide a clear guide as to the level of excess returns to housing in percentage points per annum.

In the next section we outline our methodology for estimating the excess return to housing. This approach can be applied at the level of the individual home and takes account of risk. Section 3 undertakes a detailed application of this methodology to the Sydney housing market from 2003Q1 to 2011Q2 and discusses the results. In the final section we provide some concluding comments.

\section{Estimating Excess Returns at a Disaggregated Level}

In constructing estimates of the return to housing it is necessary to have a clear idea of the particular type of agents that we are considering and their behavior. The residential real estate ownership market is usually made up of two distinct groups; owner-occupiers and 
investors. Our focus is on the former, which is invariably a much larger group than the latter. ${ }^{2}$ This is important for the setup of the model but also for the tax treatment of capital gains, one of the key components of the return to housing. In effect owner-occupiers in Australia pay no tax on any capital gains in the value of their home. This favorable tax treatment will be taken account of in constructing the excess returns to housing. We consider an owner who lives in their home and owns it freehold, without any encumbrances. The counterfactual then, from this investment in owner-occupied housing, is for the household to instead rent a comparable dwelling and take the capital which would otherwise have been tied up in the home and employ it elsewhere. If they rent rather than own they will avoid paying the costs of homeownership - property taxes, insurance, depreciation and maintenance. Or more accurately they will pay this indirectly through their rent. Each of these two options implies some level of welfare. It is the difference in welfare, measured in monetary terms, that we call the excess return to housing.

To outline the framework more formally, let $p_{t}\left(\mathbf{z}_{j}\right)$ denote the price for some dwelling with characteristics vector $\mathbf{z}_{j}$ at the start of year $t, r_{t}\left(\mathbf{z}_{j}\right)$ denotes the rent, $\delta_{t}\left(\mathbf{z}_{j}\right)$ is the annual cost of homeownership as a fraction of the dwelling price, and $i_{t+1}$ is the after tax return available from some alternative investment over period $t$. An important part of the contribution of the paper is the estimation of price and rent series, and excess returns, for a variety of characteristics vectors $\mathbf{z}_{j}$ so we have been careful to emphasize that point with our notation. However, for brevity we will use a subscript $j$ to denote this dependence so, for example, $p_{t}\left(\mathbf{z}_{j}\right)$ becomes $p_{j t}$. Finally, let $\mathrm{U}($.$) be the household's additively separable utility$ function over wealth and housing services. The utility function provides the mechanism by which we can balance risk against return. We suppose that households either rent or own the same quality home so the difference in utility between the two options is solely related to the wealth outcomes. Let us consider the case of a year. The wealth outcome for the renter is equal to the amount of capital the household has minus the rent they have to pay-for simplicity we assume this is paid in lump sum at the start of the period-multiplied by the after tax return over the relevant period. The wealth outcome for owners on the other hand is a function of the stochastic appreciation rate of the home $\pi_{j t+1}\left(=p_{j t+1} / p_{j t}-1\right)$ minus the running costs. Placing these wealth outcomes into the utility function we have the renter and owner-occupier expected utility levels on the left and right hand sides respectively,

$$
\mathrm{E}_{t}\left[\mathrm{U}\left(p_{j t}\left\{1-\frac{r_{j t}}{p_{j t}}\right\}\left\{1+i_{t+1}\right\}\right)\right]=\mathrm{E}_{t}\left[\mathrm{U}\left(p_{j t}\left\{1+\pi_{j t+1}\right\}\left\{1-\delta_{j t}\right\}\left\{1-e_{j t+1}\right\}\right)\right]
$$

In addition we have defined excess returns, $e_{t}\left(\mathbf{z}_{j}\right)$ (or $e_{j t}$ ), as the fraction of the dwelling price which must be charged to the homeowner in order to make them indifferent between owning and renting. This is chosen residually to ensure the equality of the left and right

\footnotetext{
${ }^{2}$ In Australia, which is the focus of the empirical study, the rate of home ownership is around $70 \%$ according to the latest population census (ABS, 2010).
} 
hand sides of (1). If this is positive then homeowners are achieving greater expected utility than renters and vice versa.

In implementing this approach, and determining excess returns, we need to consider a number of factors including; the form of the utility function, the size of the running costs of homeownership, the time span over which (1) holds, the alternative investment option, and how to construct households' estimates of future prices and their variability.

First, we consider the alternative use of the household's funds, i.e. what is $i_{t+1}$ ? The methodology potentially allows us to compare housing with any type of investment such as shares or bonds. However, in order to keep our approach simple, and to make our results comparable with previous research, we suppose that a renting household invests their funds in a term deposit. This is similar with the counterfactual investment in Case and Shiller (1989), who chose a 1-year Treasury Bill. But in practice a term deposit is a much more readily accessible investment for a household than a government bond. Importantly, the return on a term deposit is known a priori and given the essentially zero credit risk of Australian banks it can be regarded as risk free. This simplifies some of our calculations. These returns are adjusted for a supposed marginal tax rate of $25 \%$ which is around the average marginal tax rate in Australia (Warburton and Hendy, 2006).

Second, we consider various time horizons over which the arbitrage between homeownership and renting occurs. Equation (1) has been specified for a year. Quite apart from this being a natural time unit, and being what Case and Shiller $(1989,1990)$ chose, it is also convenient because in practice rents are negotiated a year in advance. But a year might be too short a time span when considering the planning horizon of some households. So in addition to 1 year we also consider a 3 -year horizon. This is probably as long a horizon as we could practically consider given that the length of our data is only eight-and-a-half-years. Some slight extensions of (1) are required to handle the longer horizon. The terminal wealth for the homeowner now reflects price appreciation over the 3 years as well as the annual running costs of homeownership while the evolution of the renter's wealth must respect the annual flow of rental payments. The 3-year condition equivalent to (1) is somewhat messier and hence is relegated to Appendix 6.1. One of the key features of the 3-year horizon is that it introduces greater uncertainty into the house price outcome. However, it also introduces uncertainty for the renter given that their payments in years 2 and 3 are unknown. This will make home ownership appear more attractive because, as argued in Sinai and Souleles (2005), it provides a hedge against rent risk.

Third, condition (1) is an ex ante relationship. It links expected price and rental movements with expected investment returns. But in practice households' expectations are not known and neither is the degree of uncertainty regarding these forecasts. Like Case and Shiller $(1989,1990)$ we suppose that expectations are rational in the sense that the mean of the expected change in prices is equal to the ex post change. This is not uncontroversial. Gatzlaff (1995) has argued that one of the reasons that housing returns may have been so 
high in Case and Shiller (1989, 1990) was because of non-rational expectations. However, there seems little practical alternative to this approach short of a fully fledged econometric model of expectations. In order to obtain an estimate of the uncertainty around this forecast we use the sample average variance of price changes over the time period examined.

Fourth, we look to the literature for some guidance about the appropriate choice of the annual running costs of homeownership. The relatively high running costs associated with housing is one of the key characteristics of the asset class compared with stocks or bonds. Harding, Rosenthal and Sirmans (2007), using the American Housing Survey, estimate that the loss in value due to depreciation and the cost of homeowner's maintenance expenditures is around $2.5 \%$ of the total value of the home annually. This is clearly a very significant cost for owners. We use this figure of $2.5 \%$ in our calculations, setting $\delta_{j t}$ equal to this number across all time periods, regions and property types. Though we note that because this figure does not include other running costs, such as taxes and insurance, it is likely to be an underestimate meaning our calculations may make housing look somewhat more attractive than it really is. Interestingly, though Case and Shiller (1990) did not have the benefit of this recent research on home ownership costs this is also the same figure they used.

Finally, we suppose that utility over wealth takes the well known power utility functional form (see for example, Campbell and Viceira, 2002),

$$
\mathrm{U}(x)=\left\{\begin{array}{cc}
\frac{x^{1-\phi}}{1-\phi}, & \phi \neq 1 \\
\ln (x), & \phi=1
\end{array}\right.
$$

This functional form is useful; it is simple yet by varying $\phi$ it can reflect different levels of risk aversion. Here $\phi$ represents the coefficient of constant relative risk aversion (CRRA),

$$
\phi=-\frac{x \mathrm{U}^{\prime \prime}(x)}{\mathrm{U}^{\prime}(x)}
$$

The literature points towards a value of $\phi$ that is greater than one and anything from 1 to 8 is plausible (see Attanasio, Banks and Tanner, 2002; Vissing-Jorgensen, 2002). According to Hasanov and Dacy (2009) a value of 4 or 5 leads to portfolios that are similar to those observed in the real world. Given a degree of uncertainty around the appropriate $\phi$ we choose various values. In particular we will estimate excess returns for $\phi=0,2,4,8$. With $\phi=0$ there is no risk aversion while a value of $\phi=8$ is high but not entirely implausible, at least for some households. Our preferred value is $\phi=4$, which is near the center of researchers' estimates in the literature. The power utility functional form is also convenient because in simple situations, such as our 1-year horizon where there is home appreciation uncertainty but no rent uncertainty, the analytical solution to the estimation of excess returns can be derived. If $1+\pi_{j t+1}$ is lognormally distributed with mean parameter $\mu_{j t+1}$ and variance $\sigma_{j}^{2}$ then we show in Appendix 6.2 that excess returns in (1) take the form,

$$
e_{j t+1}=\mu_{j t+1}+\frac{r_{j t}}{p_{j t}}-\delta_{j}-i_{t+1}+\frac{(1-\phi)}{2} \sigma_{j}^{2}
$$


Examining this expression we can see the excess return is equal to the expected capital gain plus rental yield minus the costs of homeownership and the reference rate. Also there is a downward adjustment for the variability of the expected capital gain mediated by the level of risk aversion. The larger is $\sigma_{j}^{2}$ and $\phi$ the smaller is the excess return. More generally, however, it may not be so straightforward to derive analytical solutions to (1). Such as when we adopt a 3-year horizon where there is now variance on both the left and right hand sides of (1) and potentially covariance between prices and rents. In such cases we will estimate the excess returns by first simulating a large number of realizations of (1) from the distribution of rent and sales price appreciation. Then we will solve an optimization problem which finds $e_{j t+1}$ which best fits these simulated values. Confidence limits for our estimates of excess returns are constructed using a bootstrap method. We re-sample from the basic price and rent data, re-estimate the indexes for each type of housing and construct fresh estimates of the excess returns. While computationally intensive this is an effective approach for constructing confidence limits in such a complex situation.

With this framework we can proceed to construct estimates across time, and across various dwelling configurations, of the excess returns to housing in Sydney. The rest of the paper is devoted to the implementation of this approach in practice and an evaluation of the empirical results.

\section{An Application to Sydney's Housing Market}

In order to demonstrate the application of our methodology we evaluate the excess returns to housing in Sydney, Australia from 2003Q1 to 2011Q2. For this we require detailed data on dwelling sale prices and rents and their characteristics. The sales data we use comes from Australian Property Monitors (APM) and includes a virtual census of the homes sold in Sydney over the period. The characteristics data include information on the property type (house or unit/condominium) and the number of bedrooms and bathrooms of the dwelling. Our rental data comes from a major internet listing service and includes the dwelling characteristics above as well as the advertised rent for the property by the vendor. While these are not strictly transaction prices they should fairly accurately represent the actual rent paid for the home as, unlike in the home purchase market, there is generally not a great deal of negotiation over rental prices. The availability of such detailed rental data is an important advantage of our study. Previous researchers have, because of a lack of such data, had to use strong assumptions, and an element of guess work, to construct estimates of the rental yield.

With these data our objective is to estimate the prices of particular types of dwellings in different regions of the city. With regard to this latter point we divide Sydney into fourteen regions. They are; Inner Sydney, the Eastern Suburbs, the Inner West, the Lower North Shore, the Upper North Shore, Mosman and Cremorne, Manly-Warringah, the North Western Suburbs, the Western Suburbs, Parramatta Hills, Fairfield-Liverpool, Canterbury- 
Bankstown, St George and Cronulla-Sutherland. These regions are fairly well recognized real estate sub-markets in Sydney. They are used by real estate listing services in various search engines and by real estate agents in discussing market developments and they will be important in our formulation of the hedonic function. The distribution of these regions can be seen in Figure 1. We propose to estimate the price and excess returns in each of these regions segmented by property type and the numbers of bedrooms and bathrooms.

Figure 1: Sydney's Regions

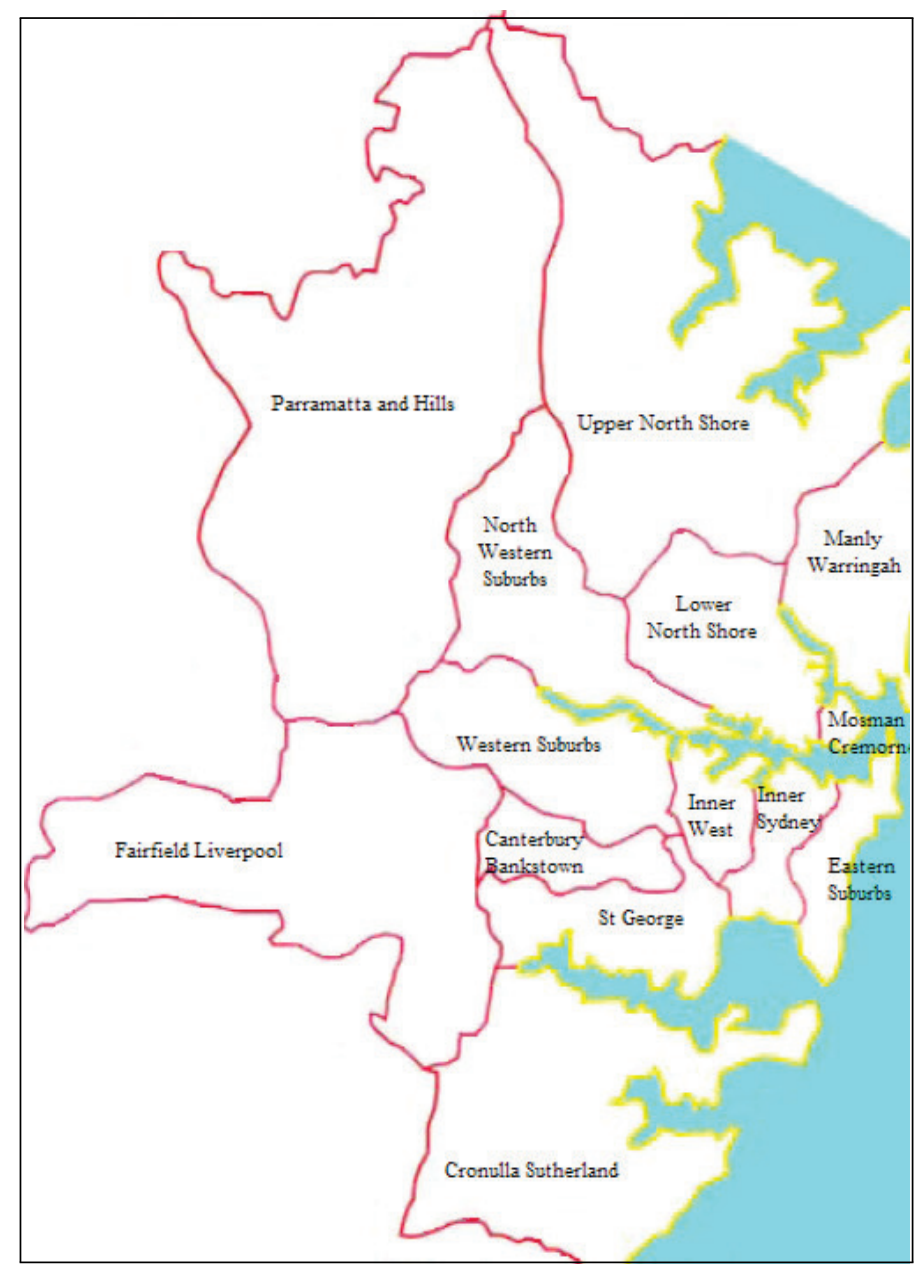

Our data is summarized in Table 1. We present the means and standard deviations of the dwelling prices, rents and the characteristics - number of bedrooms, bathrooms and the binary variable 'house', which is equal to one if the dwelling is a house and zero if it is a unit/condominium. These are broken down by the 14 regions.

A number of features to note regarding the data. First, both the sale price and rental data sets are large. There are 1,950,672 observations in total. The size of the data will help us to estimate potentially quite complex hedonic regression models. The rental data set has many more observations than the sales data, 1.5 million compared with around 400,000. This reflects the fact that properties sell only infrequently but rental vacancies are listed much more often. 
Table 1: Summary Statistics

\begin{tabular}{|c|c|c|c|c|c|c|c|c|c|}
\hline & \multirow{2}{*}{$\begin{array}{c}\text { Number } \\
\text { of Obs. }\end{array}$} & \multicolumn{4}{|c|}{ Mean } & \multicolumn{4}{|c|}{ Standard Deviation } \\
\hline & & Price $(\$)$ & House & Beds & Baths & Price $(\$)$ & House & Beds & Baths \\
\hline \multicolumn{10}{|l|}{ Sale Prices } \\
\hline Inner Sydney & 24,945 & 655,372 & 0.24 & 1.95 & 1.43 & 453,990 & 0.43 & 0.85 & 0.55 \\
\hline Eastern Suburbs & 38,261 & 994,239 & 0.43 & 2.52 & 1.48 & 709,033 & 0.50 & 0.95 & 0.63 \\
\hline Inner West & 27,424 & 764,952 & 0.69 & 2.45 & 1.41 & 405,569 & 0.46 & 0.87 & 0.57 \\
\hline Lower North Shore & 25,159 & 904,590 & 0.49 & 2.63 & 1.60 & 564,430 & 0.50 & 1.02 & 0.65 \\
\hline Upper North Shore & 24,954 & 848,843 & 0.81 & 3.42 & 1.94 & 421,962 & 0.39 & 0.95 & 0.69 \\
\hline Mosman and Cremorne & 10,649 & $1,067,200$ & 0.37 & 2.48 & 1.54 & 810,291 & 0.48 & 1.01 & 0.65 \\
\hline Manly-Warringah & 32,304 & 876,755 & 0.54 & 2.77 & 1.64 & 563,008 & 0.50 & 1.05 & 0.69 \\
\hline North Western Suburbs & 30,548 & 682,467 & 0.75 & 3.11 & 1.70 & 354,714 & 0.43 & 0.96 & 0.69 \\
\hline Western Suburbs & 31,665 & 528,266 & 0.55 & 2.69 & 1.49 & 309,546 & 0.50 & 0.88 & 0.59 \\
\hline Parramatta Hills & 35,341 & 499,291 & 0.82 & 3.29 & 1.74 & 198,413 & 0.39 & 0.88 & 0.69 \\
\hline Fairfield-Liverpool & 29,891 & 382,195 & 0.83 & 3.14 & 1.47 & 150,241 & 0.38 & 0.83 & 0.62 \\
\hline Canterbury-Bankstown & 16,804 & 408,089 & 0.60 & 2.72 & 1.33 & 179,250 & 0.49 & 0.83 & 0.57 \\
\hline St George & 40,674 & 550,985 & 0.65 & 2.79 & 1.48 & 245,584 & 0.48 & 0.90 & 0.63 \\
\hline Cronulla-Sutherland & 26,835 & 627,303 & 0.68 & 2.98 & 1.62 & 343,954 & 0.47 & 0.98 & 0.67 \\
\hline All Regions & 395,454 & 699,324 & 0.60 & 2.78 & 1.56 & 407,856 & 0.46 & 0.92 & 0.64 \\
\hline \multicolumn{10}{|l|}{ Rents $^{\dagger}$} \\
\hline Inner Sydney & 174,019 & 574 & 0.16 & 1.73 & 1.36 & 286 & 0.36 & 0.77 & 0.52 \\
\hline Eastern Suburbs & 231,876 & 595 & 0.25 & 2.13 & 1.30 & 317 & 0.43 & 0.83 & 0.52 \\
\hline Inner West & 150,292 & 496 & 0.47 & 2.09 & 1.29 & 212 & 0.50 & 0.83 & 0.50 \\
\hline Lower North Shore & 137,126 & 568 & 0.28 & 2.17 & 1.40 & 283 & 0.45 & 0.92 & 0.57 \\
\hline Upper North Shore & 56,685 & 632 & 0.69 & 3.07 & 1.77 & 315 & 0.46 & 1.03 & 0.69 \\
\hline Mosman and Cremorne & 70,879 & 596 & 0.20 & 2.06 & 1.33 & 343 & 0.40 & 0.86 & 0.55 \\
\hline Manly-Warringah & 99,065 & 594 & 0.33 & 2.28 & 1.41 & 305 & 0.47 & 0.96 & 0.60 \\
\hline North Western Suburbs & 100,942 & 434 & 0.56 & 2.63 & 1.44 & 186 & 0.50 & 0.93 & 0.60 \\
\hline Western Suburbs & 139,113 & 398 & 0.40 & 2.36 & 1.37 & 156 & 0.49 & 0.79 & 0.53 \\
\hline Parramatta Hills & 96,052 & 381 & 0.63 & 2.80 & 1.52 & 145 & 0.48 & 0.91 & 0.61 \\
\hline Fairfield-Liverpool & 79,816 & 324 & 0.69 & 2.76 & 1.30 & 103 & 0.46 & 0.83 & 0.51 \\
\hline Canterbury-Bankstown & 52,814 & 330 & 0.43 & 2.40 & 1.18 & 108 & 0.50 & 0.74 & 0.43 \\
\hline St George & 116,190 & 399 & 0.50 & 2.42 & 1.29 & 137 & 0.50 & 0.83 & 0.52 \\
\hline Cronulla-Sutherland & 50,349 & 442 & 0.50 & 2.53 & 1.40 & 182 & 0.50 & 0.90 & 0.58 \\
\hline All Regions & $1,555,218$ & 483 & 0.43 & 2.39 & 1.38 & 219 & 0.46 & 0.87 & 0.55 \\
\hline
\end{tabular}

Second, the composition of homes for rent is somewhat different from those for sale. On average only $43 \%$ of rental dwellings are houses, the remainder being units. This compares with $60 \%$ of sold dwelling being houses. Rental dwellings are generally somewhat smallerhaving fewer bedrooms and bathrooms - and are more centrally located than sold properties. But it is important to note this is for the mean of the distributions. The standard deviation of the characteristics indicate that there is still significant heterogeneity in both the size and type of rental and sold dwellings. This is important because for each dwelling type we need to impute both a price and a rent in order to solve (1). The breadth and depth of the rental and sales data enable us to do this very effectively.

Third, there is clearly significant regional variability in property types and in property prices. Some central regions are obviously very expensive, most notably Mosman and Cre- 
morne, while those in the outer ring have larger and relatively cheaper homes. The extent of these regional price differences is suggestive of the existence of property sub-markets and potentially differing price and rents trends across the city.

\subsection{Constructing the Hedonic Price Indexes}

In order to construct the capital return to housing for different property types we use hedonic methods. Our objectives in this regard are two-fold. First, to construct estimates of the capital return to housing and rental costs at a disaggregated level and show that indeed these do vary significantly across property types. Second, to show that models which allow for this flexibility perform better, and are more fit for purpose, than more aggregated models.

We start by proposing a general hedonic specification. This encompasses some commonly used models but also allows for more flexible alternatives which enable us to make maximum use of the available data. The model potentially allows for flexible region- and time-specific fixed effects in the shadow prices of the characteristics. Let us use $h_{i t r}$ to denote either a dwelling sale price $\left(p_{i t r}\right)$, or rental $\left(r_{i t r}\right)$, where observations are indexed by the particular dwelling $i$, time $t$ - which is quarters in our application - and region $r$, being the 14 regions previously outlined. The general hedonic model takes the form,

$$
\log \left(h_{i r t}\right)=\alpha_{r t 0}^{h}+\sum_{c=1}^{C} \alpha_{r t c}^{h} z_{i r t c}+\epsilon_{i r t}^{h}
$$

The variable $z_{i t r c}$ denotes the value of characteristic $c$ for a particular observation and the various $\alpha_{r t c}^{h}$ are the shadow price coefficients which we will parameterize and estimate. The characteristics are those discussed above; property type (house or unit/condominium), number of bedrooms and number of bathrooms as well as an intercept. Our model is potentially quite flexible in that, as indicated by the subscript, we can estimate different shadow prices for each characteristic in each time period and region. Moreover, we do not place any restrictions upon the rent and price equations such as forcing their parameters to be constant. Such flexibility in both the spatial and temporal dimension is likely to be important. The spatial variation in property prices is well documented (Basu and Thibodeau, 1998; Gelfand et al, 2004; Bourassa, Cantoni and Hoesli, 2010) while Pakes (2003) argued that there is little reason to believe that hedonic shadow prices should be fixed across time. They represent the equilibrium outcome of the continually evolving forces of supply and demand. Hence temporal as well as spatial flexibility should be built into the hedonic model. Specification (5) provides a simple way of doing this without having to estimate computationally intensive spatial and/or temporal functions. In selecting a hedonic model and illustrating the importance of allowing for disaggregated price movements we consider various specializations of equation (5).

Perhaps the simplest approach, and one that has been widely estimated in the hedonic literature is the time-dummy hedonic model (Haughwout, Orr and Bedoll, 2008; Eurostat, 
2011). This is what we call Model A. Here the shadow prices are fixed across time and regions except for the intercept which is allowed to vary across time, that is $\alpha_{r t 0}^{h}=\beta_{t 0}^{h}$ and for $c>0$ we have $\alpha_{r t c}^{h}=\beta_{c}^{h}$, where the $\beta$ 's are the parameters to estimate. In essence, these are the sort of assumptions which are implicit in the models that have been previously used in the literature with all dwellings assumed to have the same temporal price trends. A more flexible alternative is Model $\mathrm{B}$ which allows for regional heterogeneity in the shadow prices and the temporal price trend, $\alpha_{r t 0}^{h}=\beta_{r t 0}^{h}$ and for $c>0$ we have $\alpha_{r t c}^{h}=\beta_{r c}^{h}$. Model C adds to this by including separable temporal variation in the characteristics' shadow prices, $\alpha_{r t 0}^{h}=\beta_{r t 0}^{h}$ and for $c>0$ we have $\alpha_{r t c}^{h}=\beta_{r c}^{h r}+\beta_{t c}^{h t}$. However, none of these models allow for any interaction between temporal price trends and spatial price drivers other than for the intercept. Model $\mathrm{D}$ builds upon Model $\mathrm{C}$ by including interactions between the region and the year. This allows the shadow prices to change differently across years. As usual we set $\alpha_{r t 0}^{h}=\beta_{r t 0}^{h}$ while for $c>0$ we allow spatio-temporal trends in prices by interacting region with year. We express this as, $\alpha_{r t c}^{h}=\beta_{r t[y] c}^{h r}+\beta_{t c}^{h t}$ where the subscript $t[y]$ indicate that there is yearly temporal variation. Finally, in Model E we allow for a full range of spatial and temporal interactions with the dwelling characteristics so separate shadow prices are estimated in each time period and region for each characteristic, i.e. we require the full set of subscripts such that $\alpha_{r t c}^{h}=\beta_{r t c}^{h}$. However, this model is computationally burdensome given the large number of parameters and the size of our data set.

Table 2 outlines the performance of each model with regard to various model selection criteria. These criteria - the Akaike Information Criterion (AIC), the Bayesian Information Criterion (BIC) (see Greene, 2008) and the Cross Validation Criterion (CVC)-provide some basis upon which to evaluate the various models. The first two selection criteria are essentially measures of the explained sum of squares penalized for the addition of extra parameters. The final measure, the CVC, is perhaps most relevant for our purposes. It measures the out-ofsample forecasting performance of the models. The CVC is calculated as the sum of the squared errors when each observation in turn is withheld from the estimation data set and all other observations are used to try and predict it. In this case, like for the AIC and BIC, a lower value is preferred.

The performance of the various models provides some clues as to the existence or otherwise of disaggregated price trends. Significantly in this regard the time-dummy method, Model A, which assumes a constant city-wide price trend, is soundly rejected on the basis of all model selection criteria. It is the worst performing model. Model B, which only allows for regional price effects, also performs badly on the basis of our three criteria. The remaining models do better. Model D is preferred on the basis of all three criteria for the sales price data while Model E is preferred, again for all three criteria, for rents. But note that for rents the CVC for Model E is just $0.09 \%$ lower than for Model D yet has almost twice as many parameters, 1,905 in all. Given the size of the data set there are significant computational savings to be had from estimating a smaller model and to estimating the same model for sale prices and 
Table 2: Hedonic Regression Model Selection Criteria

\begin{tabular}{|c|c|c|c|c|c|c|}
\hline & \multicolumn{2}{|c|}{ Number of: } & \multirow[t]{2}{*}{$R^{2}$} & \multicolumn{3}{|c|}{ Model Selection Criteria } \\
\hline & Obs. & Parms. & & AIC & BIC & CVC \\
\hline \multicolumn{7}{|l|}{ Model A: } \\
\hline Sale Prices & 395,454 & 52 & 0.6803 & $-551,841$ & $-947,295$ & 36,038 \\
\hline Rents & $1,555,218$ & 52 & 0.6812 & $-2,760,715$ & $-4,315,933$ & 96,954 \\
\hline \multicolumn{7}{|l|}{ Model B: } \\
\hline Sale Prices & 395,454 & 519 & 0.7031 & $-580,088$ & $-975,540$ & 33,558 \\
\hline Rents & $1,555,218$ & 519 & 0.7009 & $-2,859,018$ & $-4,414,236$ & 91,014 \\
\hline \multicolumn{7}{|l|}{ Model C: } \\
\hline Sale Prices & 395,454 & 621 & 0.7041 & $-581,262$ & $-976,714$ & 33,462 \\
\hline Rents & $1,555,218$ & 621 & 0.7025 & $-2,866,981$ & $-4,422,199$ & 90,552 \\
\hline \multicolumn{7}{|l|}{ Model D: } \\
\hline Sale Prices & 395,454 & 999 & 0.7051 & $-581,935$ & $-977,384$ & 33,415 \\
\hline Rents & $1,555,218$ & 999 & 0.7033 & $-2,870,814$ & $-4,426,031$ & 90,333 \\
\hline \multicolumn{7}{|l|}{ Model E: } \\
\hline Sale Prices & 395,454 & 1,905 & 0.7062 & $-581,467$ & $-976,903$ & 33,488 \\
\hline Rents & $1,555,218$ & 1,905 & 0.7040 & $-2,872,475$ & $-4,427,688$ & 90,252 \\
\hline
\end{tabular}

rents. So while Model E is strictly preferred for rents we propose to instead use Model 4 which performs almost as well. We investigated the consequences of this choice on subsets of the data and the resulting rent indexes were very similar. Hence this choice is unlikely to have had any significant effect on the results.

From our selected model we can obtain imputed sale, $\hat{p}_{t}\left(\mathbf{z}_{j}\right)$, and rental prices, $\hat{r}_{t}\left(\mathbf{z}_{j}\right)$, for houses of any particular configuration, $\mathbf{z}_{j}$. This is just what is required in (1). In fact we will construct such estimates of dwelling prices and rents for each region, structure type (house or unit/condominium), up to 5 bedrooms and 3 bathrooms. That is for $420(=14 \times 2 \times 5 \times 3)$ different property configurations. This enables us to evaluate (1) for each of these and construct estimates of the excess returns for many different types of housing.

Let us examine some of the results from the estimation of our hedonic regression. To illustrate the diversity of price trends across Sydney over the period we plot price indexes for a house with 3 bedrooms and 2 bathrooms, one of the most common dwelling configurations in our sample, in a representative selection of regions - the Eastern Suburbs, the Inner West, the Upper North Shore and Cronulla-Sutherland. The results are shown in Figure 2a. What is striking is the strong evidence of regional dispersion in price appreciation. Prices rose by $37.5 \%$ in the Inner West but by just $21.8 \%$ in Cronulla-Sutherland. Rental growth, shown in Figure 2b, has been stronger on average and still presents significant dispersion in price trends - particularly after 2007. Over the period Cronulla-Sutherland experienced relatively high growth of $48.6 \%$ while in the Eastern Suburbs growth was comparatively poor at $35.4 \%$.

Figures $3 \mathrm{a}$ and $3 \mathrm{~b}$ explore sub-regional price trends by plotting sale prices and rents for different types of homes in the Eastern Suburbs. There is evidence of distinct price trends 
Figure 2: Price Indexes (Selected Regions, House, 3 Beds, 2 Baths)

(a) Sale Prices

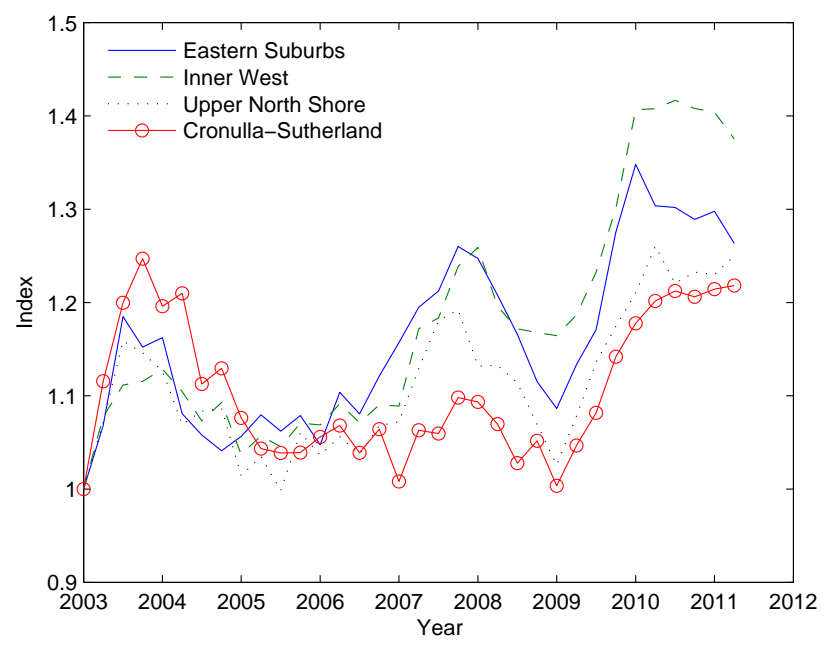

(b) Rents

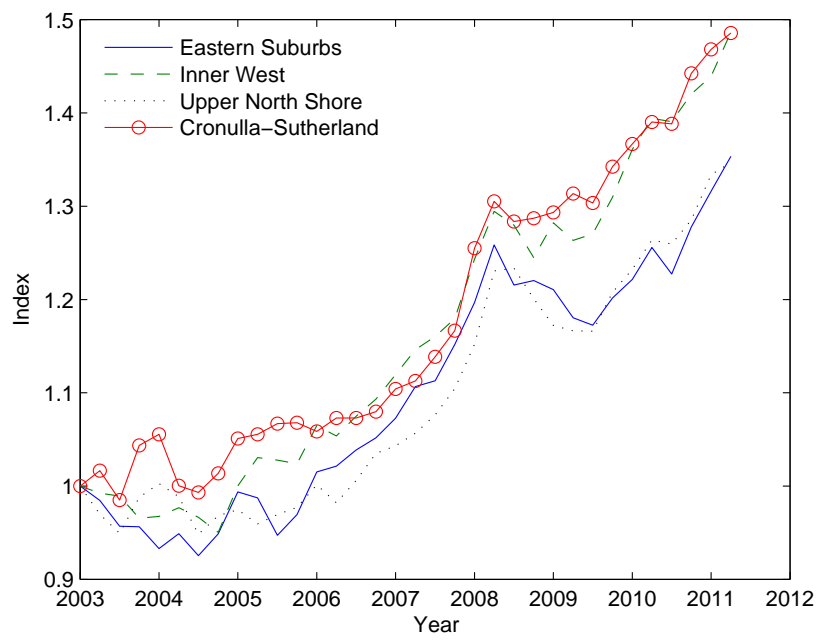

even at the sub-regional level between different property types. In the Eastern Suburbs sales price growth has been weak overall, but much more so through the mid-2000s for units with 2 bedrooms and 1 bathroom than for houses. On the other hand rentals for this property type have risen much more strongly than for houses.

These diverse region- and property type-specific price trends are estimated quite accurately. We constructed confidence intervals around these indexes by using a bootstrap method, stratified by time period and region. In all 250 estimates were obtained from the

Figure 3: Price Indexes (Selected Property Types, Eastern Suburbs)

(a) Sale Prices

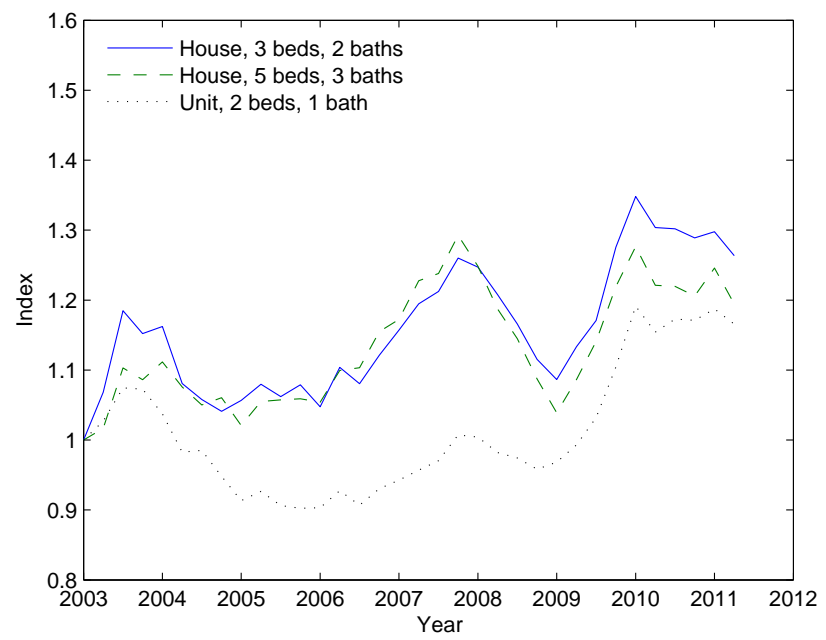

(b) Rents

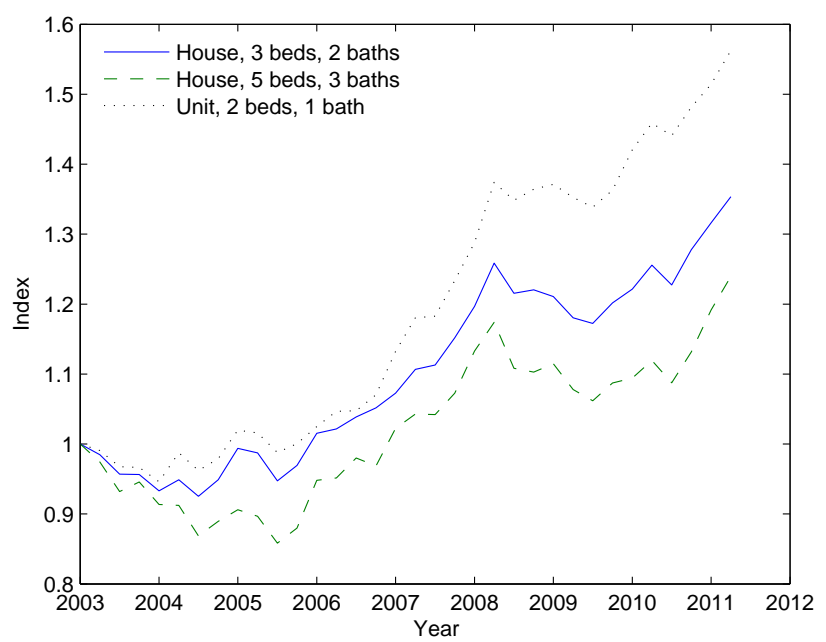


Figure 4: Confidence Intervals (Eastern Suburbs, House, 3 Beds, 2 Baths)

(a) Sale Prices

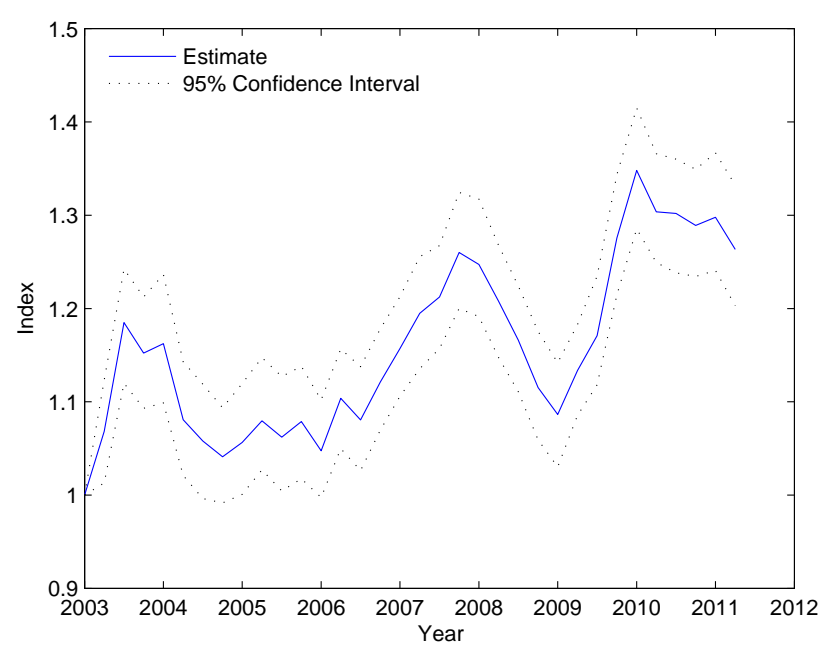

(b) Rents

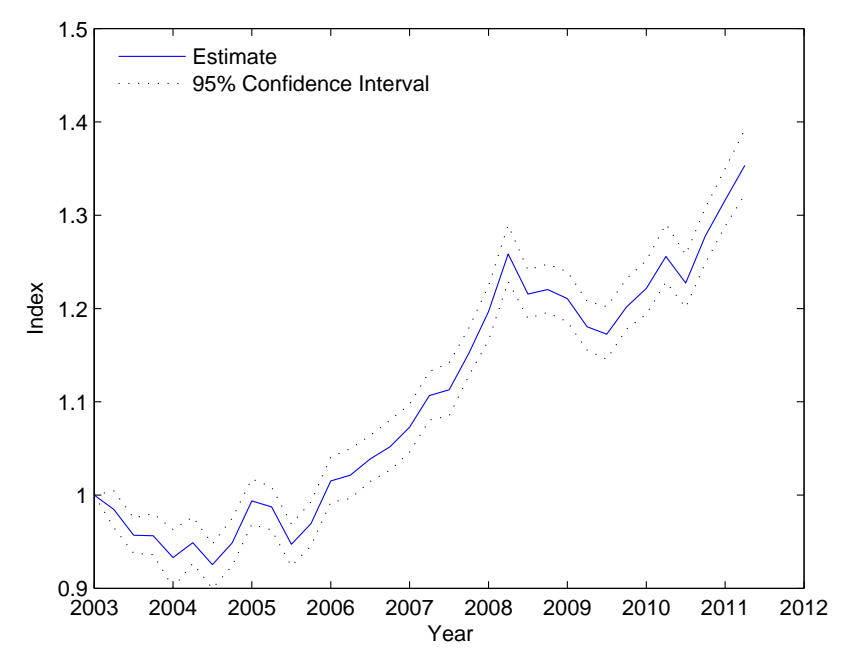

bootstrap samples and from this we formed $95 \%$ confidence intervals. To illustrate the size of these confidence intervals we plotted those for a house with 3 bedrooms and 2 bathrooms in the Eastern Suburbs in Figure 4a for sale prices and Figure 4b for rents. These were fairly typical. The tightness of the bounds indicate that many of the differences in price movements seen between regions and property types are statistically significant.

The hedonic models yield estimates for the shadow prices of the various characteristics. In Model D these varied over both time and space. Figure 5a and 5b illustrate how the shadow price for bedrooms evolved for our four selected regions. The coefficients represent the approximate percentage effect on price given we use a log transformed dependent variable. They reveal some interesting features. The two regions which are farthest from the CBD, the Upper North Shore and Cronulla-Sutherland, have the lowest shadow prices for bedrooms. This likely reflects the relative abundance of land and hence a reduced premium for space in the outlying suburbs. Interestingly, there appears to be some significant divergence in the shadow prices in the rental and price equation. For example, in the case of the Upper North Shore the average coefficient on bedrooms in the sale price equation is 0.1598 but it is 0.2120 for the rental equation. This reflects the complex interaction between supply and demand factors in local housing markets. Our estimated hedonic model is able to reflect these differences and hence faithfully represent the prices of specific types of homes and their rental cost.

Finally, it will also be useful to examine the returns to housing with those available from the other investment option considered. Figure 6 presents and index of sale prices and rents across all property types in Sydney, weighted by their empirical frequency in our data. Our sales price index is broadly consistent with other such indexes (ABS, 2011; Hansen, 2009; 
Figure 5: Bedrooms Coefficient (Selected Regions)

(a) Sale Prices

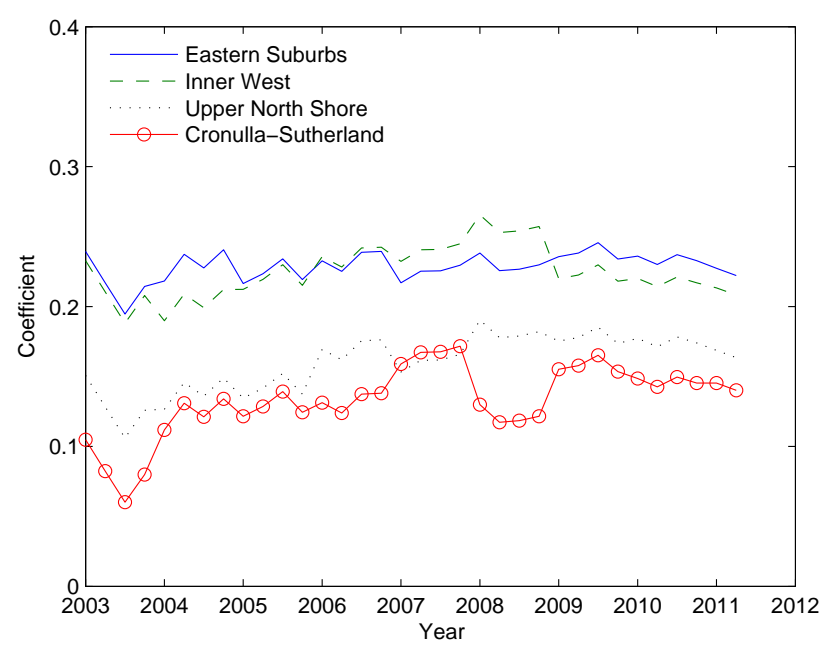

(b) Rents

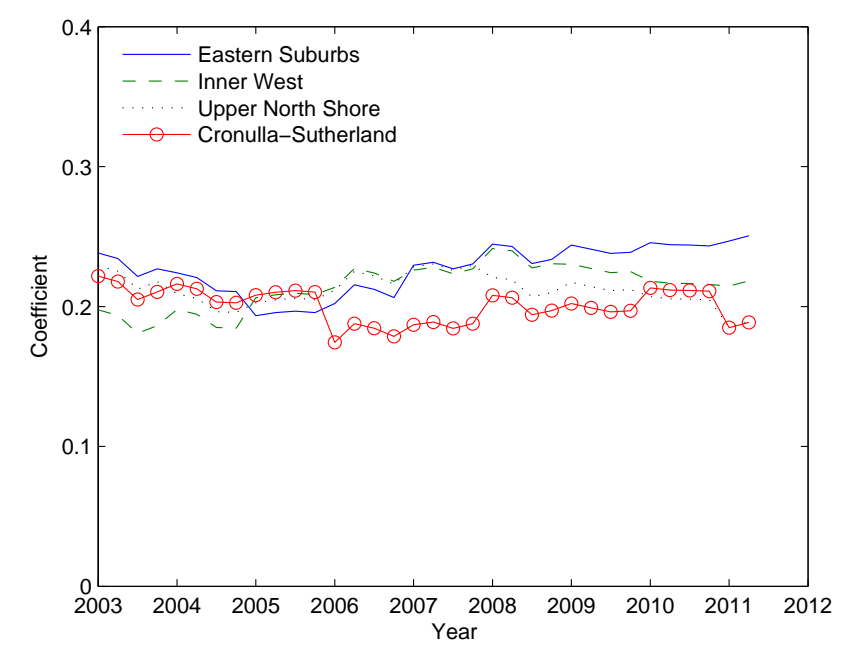

Hill, Melser and Syed, 2009). At the beginning of our series, in 2003, prices rise quickly. This was the tail-end of a housing boom which crashed over 2004. Prices were stable for sometime after this and started to rise prior to the global financial crisis (GFC) when they fell back in 2008. They posted a strong recovery following the end of the GFC but more recently have been subdued. Rents grew more strongly and consistently though paused during the 2004 decline and the GFC. Also in Figure 6 we plot an index of returns on a 1-year term deposit before tax. The fact that this has grown so much more strongly than house prices and indeed rents, is suggestive of weak excess returns to housing.

These various price and rent series from the hedonic function determine the capital gain

Figure 6: Sales Price and Rent Indexes (All Property Types) and 1-year Term Deposit

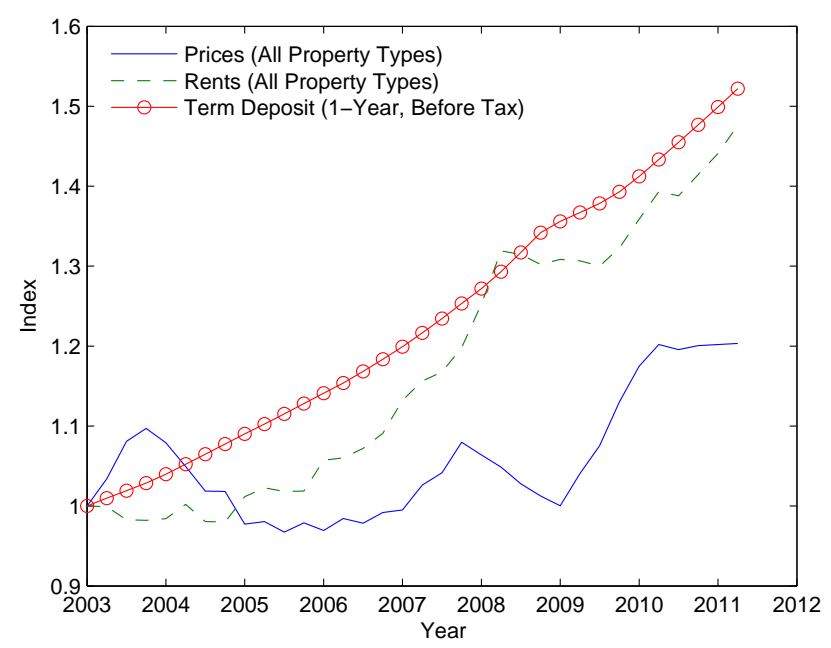


Table 3: The Returns and Covariance Matrix for Sales Prices and Rents (\%)

\begin{tabular}{|c|c|c|c|c|}
\hline \multirow[t]{3}{*}{ Appreciation Rates } & \multicolumn{2}{|c|}{ Horizon: 1 Year } & \multicolumn{2}{|c|}{ Horizon: 3 Years } \\
\hline & Sale & Rents & Sale & Rents \\
\hline & Prices & & Prices & \\
\hline \multicolumn{5}{|l|}{ Mean } \\
\hline Median & 1.79 & 4.91 & 4.78 & 18.10 \\
\hline Lower Quartile & 0.99 & 3.96 & 1.79 & 13.93 \\
\hline Upper Quartile & 2.75 & 6.04 & 8.00 & 22.06 \\
\hline \multicolumn{5}{|l|}{ Standard Deviation } \\
\hline Median & 8.12 & 5.12 & 9.84 & 8.15 \\
\hline Lower Quartile & 7.01 & 4.39 & 7.26 & 6.00 \\
\hline Upper Quartile & 9.56 & 5.89 & 13.39 & 10.06 \\
\hline \multicolumn{5}{|l|}{ Covariance Matrix } \\
\hline \multicolumn{5}{|l|}{ Median } \\
\hline Sale Prices & 65.92 & - & 96.91 & - \\
\hline Rents & 7.38 & 26.26 & 36.09 & 66.49 \\
\hline \multicolumn{5}{|l|}{ Lower Quartile } \\
\hline Sale Prices & 49.16 & - & 52.73 & - \\
\hline Rents & 0.70 & 19.31 & 13.85 & 36.06 \\
\hline \multicolumn{5}{|l|}{ Upper Quartile } \\
\hline Sale Prices & 91.47 & - & 179.39 & - \\
\hline Rents & 13.89 & 34.70 & 61.84 & 101.11 \\
\hline
\end{tabular}

or loss component of the owner-occupier's return. Hence the trends in appreciation rates for rents and sale prices for different types of dwellings are important in determining the overall results. But a key feature of our approach is that we also take account of the uncertainty around these expected outcomes. That is, for a specific property type we simulate realizations of future sale prices and rents given the mean of this distribution and the empirical covariance matrix constructed from these indexes. This is used in solving (1). The covariance matrix is important because the variability in returns influences their attractiveness given household risk aversion. Because we consider 420 different dwelling configurations there are as many sets of mean returns and covariance matrices. Table 3 summarizes these results by looking at the median rate of appreciation, median standard deviation and median parameter values for the covariance matrix, across the 420 dwelling configurations. The upper and lower quartiles are also presented. This is done at both the 1-year horizon and the 3-year horizon.

As we saw in the preceding figures, the rate of sale price appreciation was on average significantly below that of rents. The interquartile ranges indicate that for both rents and sale prices there is some heterogeneity in price change. At a 1-year horizon the median standard deviation of sales price appreciation is $8.12 \%$. This is about mid-way between the 14.24\% reported by Flavin and Yamashita (2002) and 4.89\% of Hasanov and Dacy (2009). The median annual standard deviation for rents is $5.12 \%$ which is just $63.1 \%$ of that for home prices. Interestingly, however, the ratio of the standard deviation of rents to prices rises at a 
3 -year horizon to $82.8 \%$. This indicates that the uncertainty around rents relative to dwelling prices might be more important at a longer horizon. The covariance between sale prices and rents is relatively stronger at a 3-year horizon. This is generally positive, indicating that home prices and rents move together, though in our empirical results this was not always the case.

\subsection{Calculating Excess Returns}

With our hedonic model, and using our constructed forecasts of price and rent changes and their covariance for each of the 420 dwelling configurations, we can proceed to calculate the excess return to housing using equation (1). First, to a sample of the results. Consider the excess returns over a 1-year horizon for four specific configurations of region, property type and size; (a) Eastern Suburbs, unit, 2 bedrooms, 1 bathroom, (b) Inner West, house, 3 bedrooms, 1 bathroom, (c) Upper North Shore, house, 5 bedrooms, 3 bathrooms, (d) Cronulla-Sutherland, unit, 1 bedroom, 1 bathroom. The path of excess returns for these cases, with $\phi=4$, is depicted in Figure 7a.

What is immediately evident is the cyclical nature of excess returns. There is strong evidence of the co-movement of excess returns for the different dwelling configurations in Figure 7a. Broadly this follows the trend in overall home price movements seen in Figure 6. The fall in home sales prices over 2004 and 2008 led to large negative excess returns while the jump in prices in 2009 led to a spike in returns. However, what is also evident is a significant degree of heterogeneity in these returns. For example, the Inner West house performed much better during the peaks, at the beginning of 2007 and 2009, but worse during the trough in 2008. Returns for the Cronulla-Sutherland unit were somewhat more stable. In just the four

Figure 7: Excess Returns (1-year Horizon, $\phi=4)$

(a) Various Regions, Various Property Types

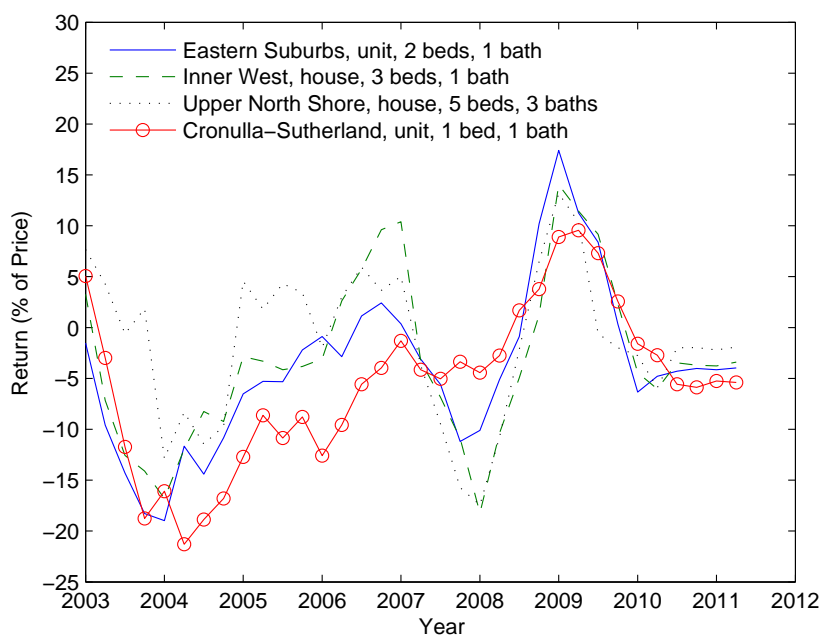

(b) Confidence Interval, Eastern Suburbs, House, 3 Beds, 2 Baths

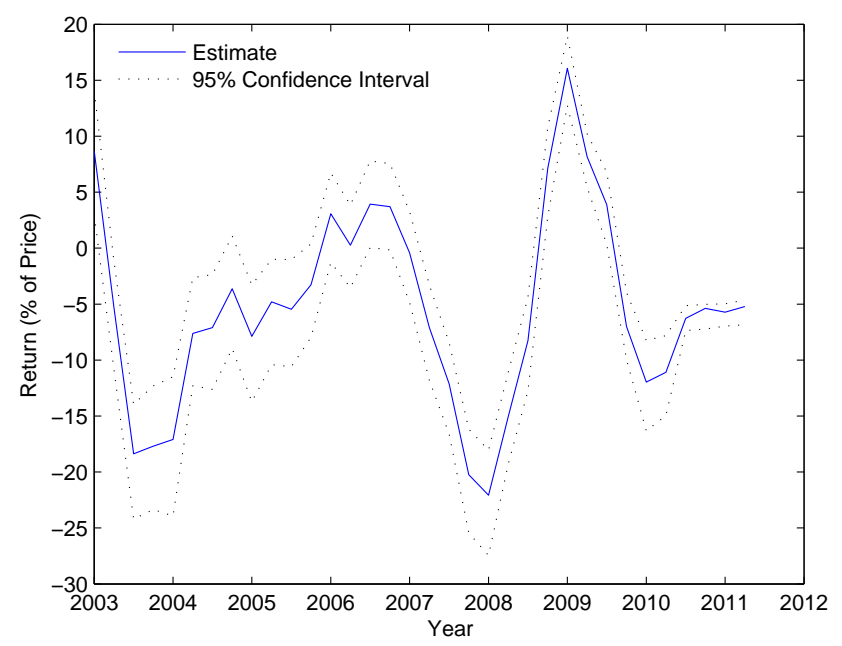


cases outlined in Figure 7a the level of excess returns sometimes differs by as much as $20 \%$. As can be seen in Figure 7b, which provides a bootstrap confidence interval, the returns series are estimated fairly accurately. Hence these differences are statistically significant.

In fact there are 420 different excess return series for each combination of horizon and risk parameter that we employ. These results are primarily summarized in Table 4 and the accompanying figures. Our focus is two-fold. First, we are interested in the overall level of excess returns across all property types over the period. Hence we include the average returns under the various scenarios we consider at the top of Table 4. Second, we investigate the heterogeneity in excess returns across a property's dimensions which was evident in Figure 7a. We do this by presenting weighted geometric average returns across each dimension. For example, in the case of regions we weight the excess returns for each dwelling configuration over time by the number of times such a dwelling is recorded in the sample. This weighting ensures that the more common dwelling types get a higher weight than those which are rarer. Note that these weights are held fixed across regions so any differences in excess returns in this case represent a pure region effect. However, in addition to the average results in Table 4 we also present the results for the few special cases shown in Figure 7a.

Let us focus first on the average excess returns across all observations for regions, property types and property sizes. These are shown in the first line of Table 4. Our best estimate of excess returns at a 1-year horizon is where we set $\phi=4$. Average excess returns over the whole sample were sharply negative at $-4.27 \%$. According to our bootstrap confidence intervals this value is statistically significantly different from zero at the $1 \%$ level. This provides a stark contrast with the returns calculated by others. As noted above, Case and Shiller (1990) found average annual excess returns, from 1970-86, of 4.22\% for Atlanta, 2.70\% for Chicago, 7.31\% for Dallas, and 20.77\% for San Francisco. Flavin and Yamashita (2002) find an annual real return to housing of $6.59 \%$ compared with effectively a zero return on bonds. What are the reasons for such a sharp divergence?

First, prior calculations took place during periods of relatively stronger house price growth. As shown in Figure 6 dwelling prices grew on average by $20.34 \%$ over the period from 2003Q1 to 2011Q2. This compares with CPI growth for Sydney of 24.92\%, indicating mildly negative real appreciation. In contrast Case and Shiller (1989) report that real house price growth per annum was essentially zero for Atlanta, $0.28 \%$ for Chicago, $2.01 \%$ for Dallas, and $3.70 \%$ for San Francisco. This is no doubt an important reason for the divergence but is unlikely to be the only reason as indicated by the fact that even Atlanta, which recorded zero real appreciation, produced much higher excess returns than we have calculated.

A second likely factor is our use of a framework that incorporates households' risk aversion and the uncertainty associated with price changes. We can get an idea of the impact of risk aversion by looking across the average excess returns for all observations for different values of $\phi$. Indeed one of the key contributions of this paper is to examine the return to housing within a model which accounts for risk. In this regard we have evaluated excess returns using four 
Table 4: Excess Returns from 2003Q1 to 2011Q2 (Annual, \% of Property Price)

\begin{tabular}{|c|c|c|c|c|c|c|c|c|c|}
\hline & \multirow{2}{*}{$\begin{array}{l}\text { Number } \\
\text { of Obs. }\end{array}$} & \multicolumn{4}{|c|}{ Horizon: 1 year } & \multicolumn{4}{|c|}{ Horizon: 3 years } \\
\hline & & $\phi=0$ & $\phi=2$ & $\phi=4$ & $\phi=8$ & $\phi=0$ & $\phi=2$ & $\phi=4$ & $\phi=8$ \\
\hline All Observations & $1,950,672$ & $-0.55^{a}$ & $-2.40^{a}$ & $-4.27^{a}$ & $-8.02^{a}$ & $0.12^{a}$ & $-1.12^{a}$ & $-2.48^{a}$ & $-5.04^{a}$ \\
\hline \multicolumn{10}{|l|}{ Some Specific Cases } \\
\hline Eastern Suburbs, unit, 2 beds, 1 bath & 98,268 & $-0.62^{a}$ & $-2.44^{a}$ & $-4.27^{a}$ & $-7.93^{a}$ & $0.51^{a}$ & $-0.91^{a}$ & $-2.34^{a}$ & $-5.09^{a}$ \\
\hline Inner West, house, 3 beds, 1 bath & 21,589 & $0.43^{b}$ & $-1.52^{a}$ & $-3.46^{a}$ & $-7.35^{a}$ & $1.37^{a}$ & $0.53^{a}$ & -0.32 & $-2.00^{a}$ \\
\hline Upper North Shore, house, 5 beds, 3 baths & 4,976 & $1.45^{a}$ & -0.11 & $-1.68^{a}$ & $-4.83^{a}$ & $1.84^{a}$ & $1.59^{a}$ & $1.33^{a}$ & 0.82 \\
\hline Cronulla-Sutherland, unit, 1 bed, 1 bath & 5,186 & $-2.24^{a}$ & $-4.04^{a}$ & $-5.84^{a}$ & $-9.45^{a}$ & $-1.87^{a}$ & $-4.52^{a}$ & $-7.19^{a}$ & $-12.07^{a}$ \\
\hline \multicolumn{10}{|l|}{ By Region } \\
\hline Inner Sydney & 198,964 & $1.22^{a}$ & $-0.86^{a}$ & $-2.94^{a}$ & $-7.12^{a}$ & $1.94^{a}$ & $0.93^{b}$ & -0.09 & $-2.14^{a}$ \\
\hline Eastern Suburbs & 270,137 & $-0.81^{a}$ & $-2.91^{a}$ & $-5.01^{a}$ & $-9.22^{a}$ & $0.23^{b}$ & $-0.75^{a}$ & $-1.73^{a}$ & $-3.67^{a}$ \\
\hline Inner West & 177,716 & 0.02 & $-1.69^{a}$ & $-3.40^{a}$ & $-6.83^{a}$ & $1.10^{a}$ & -0.02 & $-1.15^{a}$ & $-3.41^{a}$ \\
\hline Lower North Shore & 162,285 & 0.14 & $-1.32^{a}$ & $-2.77^{a}$ & $-5.70^{a}$ & $0.84^{a}$ & 0.16 & $-0.53^{b}$ & $-1.90^{a}$ \\
\hline Upper North Shore & 81,639 & 0.30 & $-1.19^{a}$ & $-2.69^{a}$ & $-5.70^{a}$ & $1.06^{a}$ & 0.07 & $-0.94^{a}$ & $-2.96^{a}$ \\
\hline Mosman and Cremorne & 81,528 & $-0.85^{a}$ & $-2.47^{a}$ & $-4.09^{a}$ & $-7.33^{a}$ & -0.03 & $-0.53^{a}$ & $-1.03^{a}$ & $-2.04^{a}$ \\
\hline Manly-Warringah & 131,369 & $-0.65^{a}$ & $-2.02^{a}$ & $-3.39^{a}$ & $-6.16^{a}$ & $-0.19^{c}$ & $-0.61^{a}$ & $-1.04^{a}$ & $-1.91^{a}$ \\
\hline North Western & 131,490 & $-0.95^{a}$ & $-3.67^{a}$ & $-6.41^{a}$ & $-11.91^{a}$ & $-0.49^{a}$ & $-2.33^{a}$ & $-4.21^{a}$ & $-7.78^{a}$ \\
\hline Western Suburbs & 170,778 & $-2.42^{a}$ & $-4.52^{a}$ & $-6.64^{a}$ & $-10.90^{a}$ & $-1.46^{a}$ & $-3.24^{a}$ & $-5.23^{a}$ & $-9.00^{a}$ \\
\hline Parramatta Hills & 131,393 & $-0.64^{a}$ & $-1.67^{a}$ & $-2.69^{a}$ & $-4.74^{a}$ & 0.10 & $-1.27^{a}$ & $-2.65^{a}$ & $-5.36^{a}$ \\
\hline Fairfield-Liverpool & 109,707 & -0.33 & $-2.66^{a}$ & $-5.01^{a}$ & $-9.71^{a}$ & -0.45 & $-3.01^{a}$ & $-6.10^{a}$ & $-11.21^{a}$ \\
\hline Canterbury-Bankstown & 69,618 & $-1.19^{a}$ & $-4.58^{a}$ & $-8.02^{a}$ & $-14.93^{a}$ & $-0.87^{b}$ & $-2.40^{a}$ & $-5.35^{a}$ & $-9.89^{a}$ \\
\hline St George & 156,864 & $-0.36^{c}$ & $-2.10^{a}$ & $-3.85^{a}$ & $-7.37^{a}$ & 0.15 & $-1.68^{a}$ & $-3.54^{a}$ & $-7.11^{a}$ \\
\hline Cronulla-Sutherland & 77,184 & $-1.46^{a}$ & $-3.41^{a}$ & $-5.36^{a}$ & $-9.27^{a}$ & $-1.29^{a}$ & $-2.93^{a}$ & $-4.59^{a}$ & $-7.82^{a}$ \\
\hline \multicolumn{10}{|l|}{ By Property Type } \\
\hline Unit & $1,093,410$ & $0.22^{c}$ & $-1.56^{a}$ & $-3.36^{a}$ & $-6.98^{a}$ & $0.97^{a}$ & $-0.46^{a}$ & $-1.99^{a}$ & $-4.85^{a}$ \\
\hline House & 857,262 & $-1.19^{a}$ & $-3.37^{a}$ & $-5.56^{a}$ & $-9.95^{a}$ & $-0.63^{a}$ & $-1.70^{a}$ & $-2.88^{a}$ & $-5.16^{a}$ \\
\hline \multicolumn{10}{|l|}{ By Property Size } \\
\hline 1 bed, 1 bath & 315,328 & $-1.12^{a}$ & $-3.36^{a}$ & $-5.62^{a}$ & $-10.16^{a}$ & $-0.40^{a}$ & $-1.90^{a}$ & $-3.67^{a}$ & $-6.96^{a}$ \\
\hline 2 beds, 1 bath & 620,998 & $-0.89^{a}$ & $-2.91^{a}$ & $-4.94^{a}$ & $-9.02^{a}$ & $-0.14^{a}$ & $-1.58^{a}$ & $-3.18^{a}$ & $-6.19^{a}$ \\
\hline 2 beds, 2 baths & 204,508 & $-0.51^{a}$ & $-2.23^{a}$ & $-3.95^{a}$ & $-7.43^{a}$ & 0.07 & $-0.96^{a}$ & $-2.05^{a}$ & $-4.15^{a}$ \\
\hline 3 beds, 1 bath & 280,311 & $-0.71^{a}$ & $-2.80^{a}$ & $-4.89^{a}$ & $-9.10^{a}$ & 0.13 & $-1.28^{a}$ & $-2.79^{a}$ & $-5.65^{a}$ \\
\hline 3 beds, 2 baths & 246,586 & $-0.31^{a}$ & $-1.94^{a}$ & $-3.58^{a}$ & $-6.89^{a}$ & $0.33^{a}$ & $-0.57^{a}$ & $-1.50^{a}$ & $-3.32^{a}$ \\
\hline 4 beds, 2 baths & 124,958 & -0.13 & $-1.95^{a}$ & $-3.77^{a}$ & $-7.44^{a}$ & $0.60^{a}$ & $-0.25^{a}$ & $-1.12^{a}$ & $-2.81^{a}$ \\
\hline 5 beds, 3 baths & 22,257 & 0.40 & $-1.68^{a}$ & $-3.77^{a}$ & $-7.98^{a}$ & $1.08^{a}$ & 0.39 & $-0.31^{a}$ & $-1.69^{a}$ \\
\hline
\end{tabular}

Note: ${ }^{a}=$ the coefficient is statistically different from zero at the $1 \%$ significance level on the basis of a two-side test, ${ }^{b}=5 \%,{ }^{c}=1 \%$.

different values for the CRRA parameter; 0, 2, 4 and 8. For the case of no risk aversion, $\phi=0$, average excess returns for a 1 year horizon are $-0.55 \%$. With a $\phi$ of 2 returns on average drop to $-2.40 \%$ and with $\phi=8$ excess returns are $-8.02 \%$. The effects of differing risk aversion can be seen even more starkly by focusing on a specific case for illustrative purposes. Consider the excess returns for an Eastern Suburbs house with 3 bedrooms and 2 bathrooms across a 1-year horizon. The results are plotted in Figure 8. Clearly, the assumptions regarding risk aversion matter a great deal for evaluating the excess returns to housing. While there 
Figure 8: Excess Returns (1-year Horizon, Eastern Suburbs, House, 3 Beds, 2 Bath, Various $\phi)$

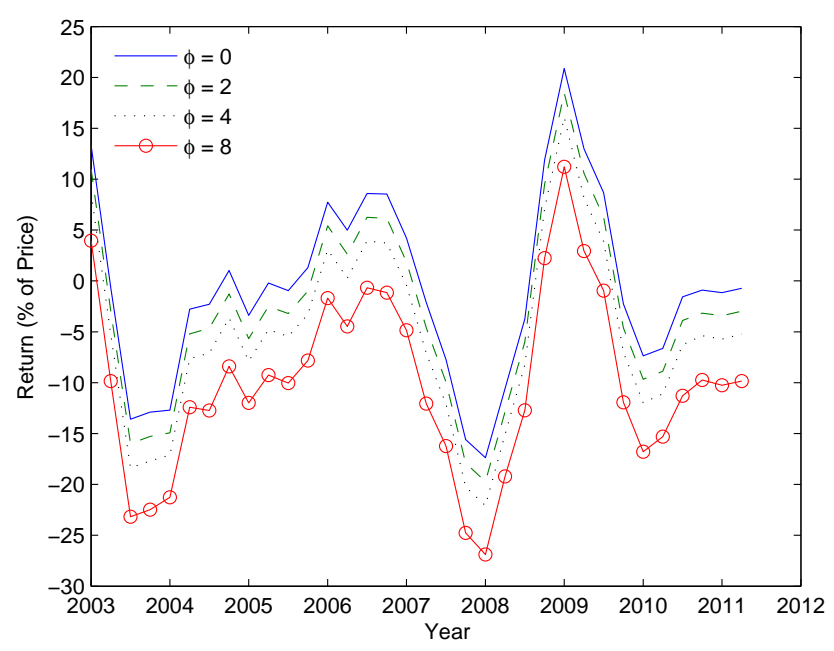

will be disagreement about the precise value that $\phi$ should take there is likely to be broader consensus that a value of around 4 is more appropriate than zero. With a 1 year horizon this would correspond to a downward adjustment of almost $4 \%$ to previously calculated excess returns which assumed no risk aversion.

Finally, it appears that previous studies may have used a somewhat higher rental yield than we observed in our data. Case and Shiller (1989) apparently used a fairly modest $5 \%$ but they raised this considerably in Case and Shiller (1990), to an average of $8 \%$. We can infer from Flavin and Yamashita (2002) that they used something around 7.5\%. ${ }^{3}$ Our calculation of rents and prices indicated that rental yields were generally well below $5 \%$. They averaged $4.32 \%$ over our sample but varied greatly across time and property types. This is illustrated in Figure 9a, which shows the rental yield for a house with 3 bedrooms and 2 bathrooms, and Figure 9b, which shows the yield for different types of properties in the Eastern Suburbs.

The results in Table 4 also show that the horizon over which condition (1) is imposed matters. If we compare the average excess returns achieved at a 1-year horizon with those using a 3-year horizon then it is invariably the latter which produces the higher excess returns. On average, for $\phi=4$, excess returns are $-4.27 \%$ for the 1 -year horizon but are $-2.48 \%$ for the 3-year horizon. The differences are larger for higher levels of risk aversion and smaller when there is less or no risk aversion. This is not entirely unexpected as the longer horizon introduces appreciation uncertainty for the renter as to what they will have to pay in years to come. This makes owning more attractive. This is exacerbated by the apparent rise in the relative variance of rents to sale prices that we found at a 3-year horizon and illustrated

\footnotetext{
${ }^{3}$ They do not explicitly assume a depreciation rate as this drops out of their formula. However, they assumed a baseline return of $5 \%$ and that homeowner costs are passed straight through to rents. If we add our assumed $2.5 \%$, which is also used by Case and Shiller (1990), then we get $7.5 \%$.
} 
Figure 9: Rental Yields

(a) Various Regions, House, 3 Beds, 2 Baths

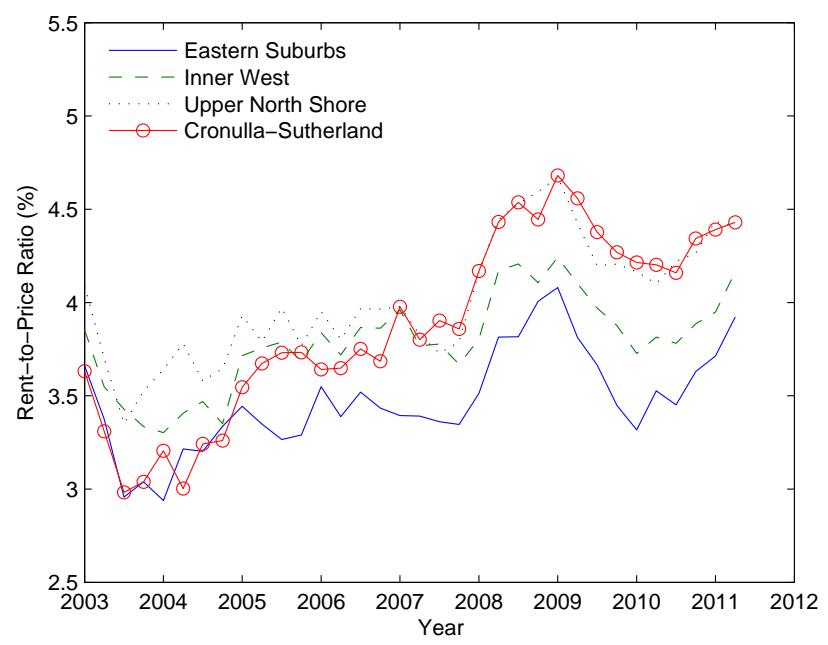

(b) Eastern Suburbs, Various Property Types

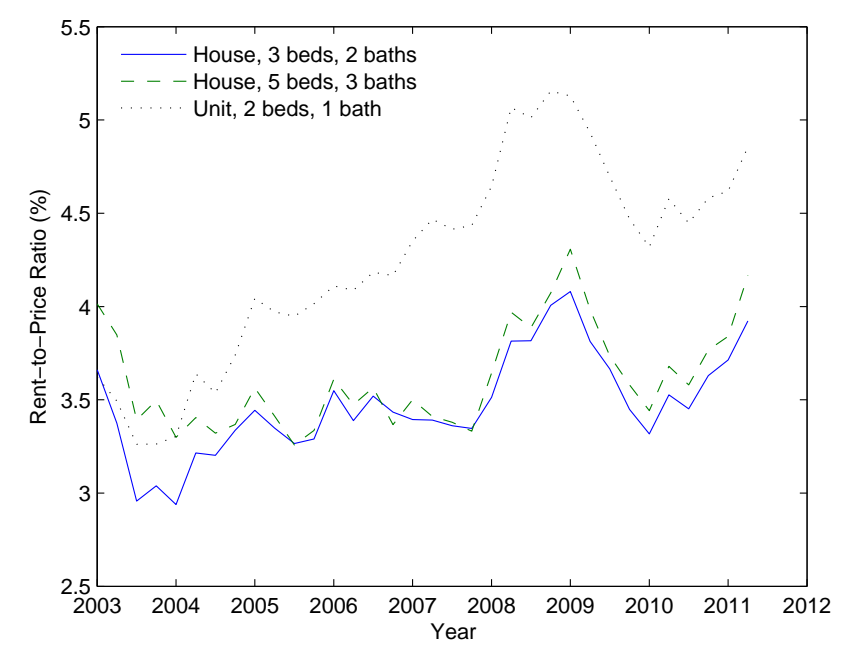

in Table 3. These results also give some empirical support to the point made by Sinai and Souleles (2005) that one of the key advantages of homeownership is its role as a rent hedge. It seems likely that if we were to extend out the horizon even further the return to housing will commensurately rise. Though this is difficult for us to investigate given the length of our data.

These results indicate that on average - over all property types, sizes and regions - we can be pretty sure that the excess returns to homeownership were not positive in our sample. Using detailed disaggregated data, a reasonable framework and incorporating realistic assumptions about risk we argue that residential real estate has not been a good investment for the average household over this period. Yet the focus on the average obscures much of the bigger picture. This is of significant heterogeneity in excess returns to housing across regions, time and property types. The remainder of Table 4 provides some clues to this heterogeneity.

If we look across the regions, at the weighted average excess returns, then it is clear that some of the heterogeneity is due to the different price paths. Figure 10a plots the excess returns across regions for a fixed dwelling type. It really matters where you purchased your dwelling. Some regions - such as Inner Sydney, the Inner West and the Upper and Lower North Shore - have had much stronger excess returns than average while others - the Western Suburbs, Canterbury-Bankstown, North Western, and the Eastern Suburbs-have performed relatively poorly producing markedly negative excess returns. However, part of the heterogeneity in returns is also due to the nature of the property, its size and its type.

Interestingly, there were higher excess returns to units as opposed to houses over the period. This is potentially important for households to know as the choice to purchase a unit or a house is often one that buyers agonize over. The reason that the return for units was 
Figure 10: Excess Returns Across Regions and Property Sizes (1-year Horizon, $\phi=4$ )

(a) Various Regions, Unit, 2 Beds, 1 Bath

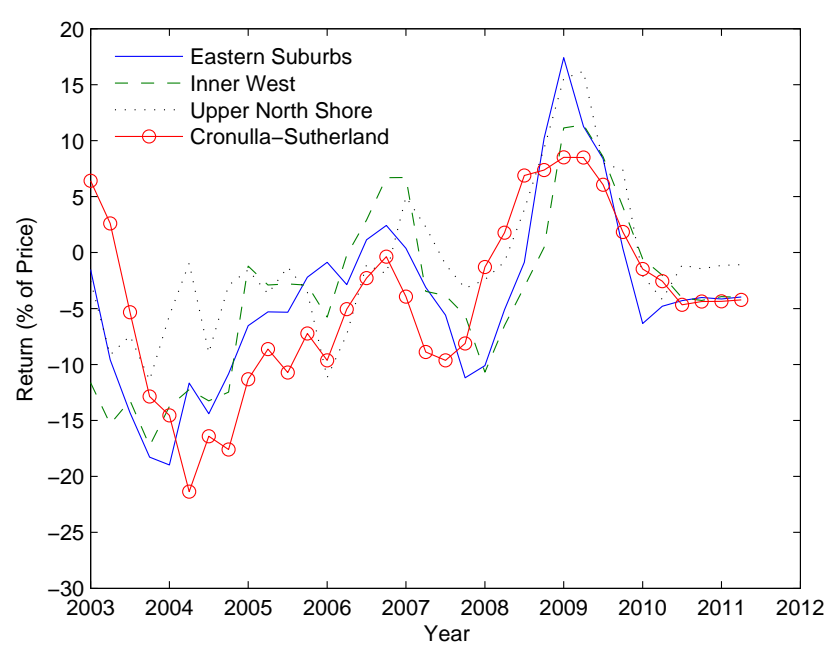

(b) Eastern Suburbs, Various Property Types

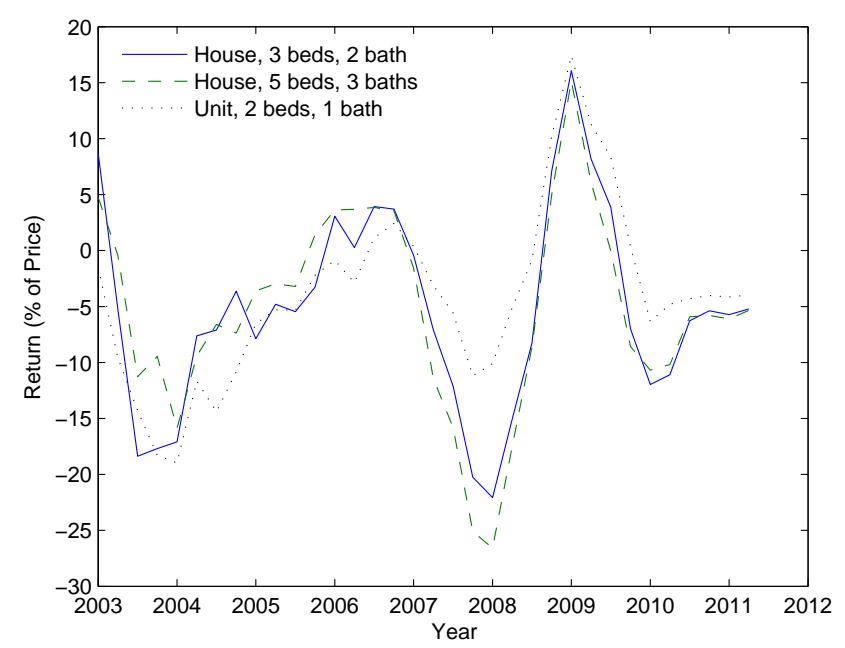

higher than that for houses was primarily because of the elevated rental yields on the former. This was seen in Figure 9b for the Eastern Suburbs but held more generally. With the prices of most property types posting only modest gains over the period the differences in rental yield were important.

The average excess returns across property sizes indicate that the smallest and largest dwellings performed the best. The fact that excess returns were stronger for larger - and generally more expensive - dwellings is consistent with Kiel and Carson (1990) who also find this. The prevailing wisdom is that as an investment opportunity becomes more expensive, and liquidity constraints make it more difficult to exploit, excess returns are likely to develop. The higher returns on smaller dwellings is primarily related to their higher rental yield. The differing returns across dwelling types is illustrated well by Figure 10b. This compares the returns for three dwelling types within the Eastern Suburbs with the differences being quite large. Most notably the smaller unit performed much better during the price downturn in 2008 .

\section{Conclusion}

Calculating the returns to housing represents a venerable tradition in the literature. We have proposed an alternative approach to this problem. Importantly this takes account of risk aversion and can be implement at a disaggregated level, essentially the level of the individual home. This approach was applied to the problem of estimating the excess returns to housing in Sydney, Australia, from 2003Q1 to 2011Q2. The results provide a new perspective on the risks and returns facing owner-occupiers. They show that excess returns were not universally 
positive for homeowners. Indeed, far from it. For reasonable levels of risk aversion returns were negative for a significant portion of the city's real estate. Our best estimate was that excess returns averaged $-4.27 \%$ per annum over the period compared with an investment in a term deposit. However, what was also apparent was that excess returns varied greatly over the cross section of home-types and regions. This means that it matters very much what type of property you bought, and where, in terms of the returns you received upon your investment. The household's level of risk aversion was also influential as was the time horizon of which we considered buying and renting.

This provides a clearer perspective of the significance of the decisions facing households when deciding what type of home to buy or whether to buy at all. The primary message arising from this is that prior work may have painted an overly sanguine and simplistic picture of owner-occupied housing as an investment asset. While it remains to apply the methodology to a broader range of cities and time periods our conclusion thus far is that the returns to housing are quite poor and much more complex than has been appreciated. In this regard we have perhaps taken some of the gloss off housing as an investment class by introducing a more practical and realistic perspective into the quantification of homeowners' returns.

\section{$5 \quad$ References}

Attanasio, O. P., J. Banks and S. Tanner (2002), "Asset Holding and Consumption Volatility," Journal of Political Economy 110(4), 771-792.

ABS (2010), Measures of Australia's Progress Catalogue No. 1370.0.

ABS (2011), House Price Indexes: Eight Capital Cities, September 2011, Catalogue No. 6416.0 .

Bailey M. J., R. F. Muth and H. O. Nourse (1963), "A Regression Method for Real Estate Price Index Construction," Journal of American Statistical Association 58(304), 933-942.

Basu, S. and T. G. Thibodeau (1998), "Analysis of Spatial Autocorrelation in House Prices," Journal of Real Estate Finance and Economics 17(1), 61-85.

Bourassa, S. C., M. Hoesli and V. S. Peng (2003), "Do Housing Submarkets Really Matter?" Journal of Housing Economics 12(1), 12-28.

Bourassa, S. C., E. Cantoni and M. Hoesli (2010), "Predicting House Prices with Spatial Dependence: A Comparison of Alternative Methods," Journal of Real Estate Research 32(2), 139-160.

Campbell, J. Y. and L. M. Viceira (2002), Strategic Asset Allocation: Portfolio Choice for Long-Term Investors, Oxford University Press, New York: US.

Cannon, S., N. G. Miller and G. S. Pandher (2006), "Risk and Return in the U.S. Housing 
Market: A Cross-Sectional Asset-Pricing Approach," Real Estate Economics 34(4), 519552 .

Case K. E. and R. J. Shiller (1989), "The Efficiency of the Market for Single-Family Homes," American Economic Review 79(1), 125-137.

Case, K. E. and R. J. Shiller (1990), "Forecasting Prices and Excess Returns in the Housing Market," Real Estate Economics 18(3), 253-273.

Eurostat (2011), Handbook on Residential Property Prices Indexes, website: www.epp.eurostat.ec.europa.eu/portal/page/portal/hicp/methodology/owner_occupied_housing_hpi/rppi_handbook.

Flavin, M. and T. Yamashita (2002), "Owner-Occupied Housing and the Composition of the Household Portfolio," American Economic Review 92(1), 345-362.

Gatzlaff, D. H. (1994), "Excess Returns, Inflation, and the Efficiency of the Housing Market," Real Estate Economics 22(4),553-581.

Gelfand, A. E., M. D. Ecker, J. R. Knight and C. F. Sirmans (2004), "The Dynamics of Location in Home Price," Journal of Real Estate Finance and Economics 29(2), 149-166.

Greene, W. H. (2008), Econometric Analysis (6th ed.), Pearson, Prentice Hall, New Jersey: US.

Hansen, J. (2009), "Australian House Prices: A Comparison of Hedonic and Repeat-Sales Measures," The Economic Record 85(269), 132-145.

Hasanov, F. and D. C. Dacy (2009), "Yet Another View on Why a Home is One's Castle," Real Estate Economics 37(1), 23-41.

Haughwout, A., J. Orr and D. Bedoll (2008), "The Price of Land in the New York Metropolitan Area," Current Issues in Economics and Finance 14(3), Federal Reserve Bank of New York, 1-7.

Hill, R. J., D. Melser and I. Syed (2009), "Measuring a boom and bust: The Sydney housing market 20012006," Journal of Housing Economics 18(3), 193205.

Kiel, K. A. and R. T. Carson (1990), "An Examination of Systematic Differences in the Appreciation of Individual Housing Units," The Journal of Real Estate Research 5(3), 301-318.

Pakes, A. (2003), "A Reconsideration of Hedonic Price Indexes with an Application to PCs," American Economic Review 93(5), 1578-1596.

Sinai, T and N. S. Souleles (2005), "Owner-Occupied Housing as a Hedge Against Rent Risk," The Quarterly Journal of Economics 120(2), 763-789.

Vissing-Jorgensen, A. (2002), "Limited Asset Market Participation and the Elasticity of Intertemporal Substitution," Journal of Political Economy 110(4), 825-853.

Warburton, R. F. E. and P. W. Hendy (2006), International Comparison of Australias Taxes, Report prepared for the Federal Treasurer Peter Costello. 


\section{Appendix}

\subsection{Equilibrium Condition for a 3-Year Horizon}

In extending (1) to a 3-year horizon we need to be aware of the flow of payments and the way in which inflation in rents and sales prices changes these. The expression for the 3-year equilibrium condition is,

$$
\begin{array}{r}
\mathrm{E}_{t}\left[\mathrm{U}\left(p_{j t}\left\{\left\{\left\{1-\frac{r_{j t}}{p_{j t}}\right\}\left\{1+i_{t+1}\right\}-\frac{r_{j t}\left(1+\tau_{j t+1}\right)}{p_{j t}}\right\}\left\{1+i_{t+2}\right\}-\frac{r_{j t}\left(1+\tau_{j t+1}\right)\left(1+\tau_{j t+2}\right)}{p_{j t}}\right\}\left\{1+i_{t+3}\right\}\right)\right] \\
=\mathrm{E}_{t}\left[\mathrm{U}\left(p_{j t}\left\{1+\pi_{j t+1}\right\}\left\{1+\pi_{j t+2}\right\}\left\{1+\pi_{j t+3}\right\}\left\{1-\delta_{j}\right\}^{3}\left\{1-e_{j t}\right\}^{3}\right)\right](6)
\end{array}
$$

Here we have used $\tau_{j t+1}$ to denote rental price inflation between periods $t$ and $t+1$ and assumed these is a constant depreciation rate $\delta_{j}$. The expression also takes account of the timing of rental payments.

\subsection{An Analytical Solution for Excess Returns in a Special Case}

Here we suppose that the relative prices, $p_{j t+1} / p_{j t}=1+\pi_{j t+1}$, are lognormally distributed with mean parameter $\mu_{j t+1}$ and variance $\sigma_{j}^{2}$. Furthermore, we just consider the 1-year horizon where rents $\left(r_{j t}\right)$ and returns $\left(i_{t+1}\right)$ are known with certainty. Then let us first note the fact that if $x_{j t+1}=1+\pi_{j t+1}$ is a log normally distributed random variable then,

$$
\log \mathrm{E}\left[x_{j t+1}\right]=\mathrm{E}\left[\log \left(x_{j t+1}\right)\right]+\frac{1}{2} \operatorname{Var}\left[\log \left(x_{j t+1}\right)\right]=\mu_{j t+1}+\frac{\sigma_{j}^{2}}{2}
$$

Now remove the common product $1 /(1-\phi) p_{j t}^{1-\phi}$ from the left and right hand sides of (1). If we take the $\log$ of the right hand side, use $(7)$ and note that $\log (1+y) \approx y$ for $\pm y$ close to zero, then,

$$
\begin{aligned}
\log \mathrm{E}_{t}\left[\left\{\left(1+\pi_{j t+1}\right)\left(1-\delta_{j}\right)\left(1-e_{j t+1}\right)\right\}^{1-\phi}\right] & =\mathrm{E}_{t}\left[\log \left\{\left(1+\pi_{j t+1}\right)\left(1-\delta_{j}\right)\left(1-e_{j t+1}\right)\right\}^{1-\phi}\right] \\
+\frac{1}{2} \operatorname{Var}\left[\log \left\{\left(1+\pi_{j t+1}\right)\left(1-\delta_{j}\right)\left(1-e_{j t+1}\right)\right\}^{1-\phi}\right] & =(1-\phi)\left\{\mu_{j t+1}-\delta_{j t}-e_{j t+1}\right\}+\frac{(1-\phi)^{2}}{2} \sigma_{j}^{2}
\end{aligned}
$$

Equating this to the left hand side of (1) and rearranging yields,

$$
(1-\phi) \log \left(\left\{1-\frac{r_{j t}}{p_{j t}}\right\}\left(1+i_{t+1}\right)\right)=(1-\phi)\left\{\mu_{j t+1}-\delta_{j}-e_{j t+1}\right\}+\frac{(1-\phi)^{2}}{2} \sigma_{j}^{2}
$$

Or,

$$
e_{j t+1}=\mu_{j t+1}+\frac{r_{j t}}{p_{j t}}-\delta_{j}-i_{t+1}+\frac{(1-\phi)}{2} \sigma_{j}^{2}
$$

